\title{
Catch me in winter! Seasonal variation in air temperature severely enhances physiological stress and mortality of species subjected to sorting operations and discarded during annual fishing activities
}

\author{
Folco Giomi - Saša Raicevich - Otello Giovanardi - Fabio Pranovi · \\ Paolo Di Muro · Mariano Beltramini
}

(C) Springer Science+Business Media B.V. 2008

\begin{abstract}
Several studies have considered the direct and indirect effects of demersal trawling on discarded species in terms of sublethal damages, survival, and stress due to the fishing processes. Nevertheless the effects of air temperature on the physiological stress and the survival of species during sorting operations were only marginally explored. This factor could be particularly important in the context of sustainable fisheries at temperate latitudes where the seasonal variation of air temperature can be particularly pronounced. In this study the seasonal effects of rapido trawling on the non-target species Liocarcinus depurator (Portunidae) in the Northern Adriatic Sea (Mediterranean Sea) have been compared by applying survival tests and considering the unbalance in
\end{abstract}

Guest editors: J. Davenport, G. Burnell, T. Cross, M. Emmerson, R. McAllen, R. Ramsay \& E. Rogan Challenges to Marine Ecosystems

F. Giomi $(\bowtie)$ P P. D. Muro · M. Beltramini

Department of Biology, University of Padova, Viale

G. Colombo 3, 35131 Padova, Italy

e-mail: folco@bio.unipd.it

S. Raicevich · O. Giovanardi

ICRAM-Istituto Centrale per la Ricerca Scientifica e

Tecnologica Applicata al Mare, Loc. Brondolo, Chioggia,

30015 Venice, Italy

F. Pranovi

Department of Environmental Sciences, University

of Venice, Venice, Italy metabolites' concentration as indicators of physiological stress. Results showed consistently higher mortalities during exposure to air in summer (temperature: $28^{\circ} \mathrm{C}$ ), which reached about $96 \%$ in $20 \mathrm{~min}$, compared to winter (temperature: $9^{\circ} \mathrm{C}$ ) when only $2 \%$ of individuals died. Furthermore trawled and emersed crabs showed significant increase of hemolymph ammonia, lactate, and glucose concentrations as effects of extreme exercise and suffocation, which was more prominent during summer, suggesting that air temperature can play an important role in determining non-target species survival.

Keywords Physiological stress .

Mortality $\cdot$ Fishing disturbance $\cdot$ Discard .

Liocarcinus depurator $\cdot$ Northern Adriatic Sea

\section{Introduction}

Fishing activity constitutes one of the major sources of ecological disturbance (sensu White \& Pickett, 1985) and alteration among human exploitation of the marine ecosystems (Williams, 1998). The effects of intense and lasting fishing have been widely investigated to assess the possible effects on marine resources and biodiversity (Jennings \& Kaiser, 1998) and to delineate effective guidelines for sustainable fisheries (Pikitch et al., 2005). The overexploitation of marine resources has been recognized to cause drastic impairments of the food web structure and the 
consequent alteration of the productivity (Pauly \& Christensen, 1995). Besides, fishing has dramatic effects on the non-target species, and the different techniques employed have been proved to cause a wide range of alterations to biodiversity and community structure (Jennings et al., 2001; Queirós et al., 2006; Tillin et al., 2006). These aspects are reflected, for example, by the pronounced imbalance in terms of damage, physiological stress, and survival among the species subjected to trawling activities. In fact during the fishing process, which includes not only capture by the fishing gear, but also the exposure on deck during commercial catch sorting operations, the individuals may suffer physical damage (Bergmann et al., 2001a; Pranovi et al., 2001) and physiological stress due to thermal shocks and exposure to air (Bergmann et al., 2001b; Gamito \& Cabral, 2003) which can lead to high mortality rates (Kaiser \& Spencer, 1995; Bergmann \& Moore, 2001). Among the discarded species, crustaceans constitute a prominent part of the total biomass and represent an excellent candidate to assess the physical and physiological effects of trawling and sorting procedures (Bergmann et al., 2001b; Pranovi et al., 2001). In particular, emersion represents, for sublittoral species, a traumatic event that induces increased physiological disruption (Burnett, 1988; Durand \& Regnault, 1998). The permanence in the emersed state causes a collapse of the gas-exchange organs like the lamellate and the filamentous gills (McMahon, 2001). The exchanges, normally occurring at the level of these organs, are reduced or blocked leading to an increase of concentration of respiratory and metabolic end products in the hemolymph and tissues. The suffocation in air is, in fact, connected with the rapid increase in hemolymph $\mathrm{CO}_{2}$. This effect, together with pronounced lactate accumulation derived from the anaerobic metabolism, causes the marked respiratory acidosis. As for the gas exchange, during emersion the excretion across gills is reduced leading to an increase of ammonia concentrations in the hemolymph and tissues (Danford et al., 2002). Moreover, the trawling and the emersion events stimulate mechanical exercise and stress for the discarded animals, and these are reflected in a pronounced hyperglycemia caused by the increased glycogen utilization (Taylor \& Spicer, 1987; Hagerman et al., 1990; Schmitt \& Uglow, 1997). These indicators have been applied to the study of the physiological effects of fishing disturbance on discarded species and, recently, to Liocarcinus depurator (Portunidae) in the Clyde Sea (Bergmann et al., 2001b). L. depurator is a species distributed in the sublittoral areas from the Mediterranean to the North Sea, and is frequently caught and discarded by demersal fishery all over the continental shelves. $L$. depurator represents a major component of the discard in the Northern Adriatic Sea fishing industry and is usually subjected to high levels of lethal and sublethal injuries during trawling (Pranovi et al., 2001). Some recent papers highlighted the role of air temperature on the survival of crustaceans during the fishing process (Cabral et al., 2002; Gamito \& Cabral, 2003).

The aim of this study is to explore the effect of seasonality, reflected by differences of water and air temperatures, as a source of mortality and physiological impairment in individuals of $L$. depurator discarded by commercial trawl fishing activity in the Northern Adriatic Sea. Accordingly, the mortality rate and the physiological disruption have been analyzed and compared during winter and summer trawls and after the subsequent exposure in air, at temperatures of $9^{\circ} \mathrm{C}$ and $28^{\circ} \mathrm{C}$, respectively.

\section{Materials and methods}

Experimental trawls and animal sampling

During March 2002 and July 2003 a total number of 8 experimental rapido tows (for fishing gear description see Hall-Spencer et al., 1999) were carried out in the Northern Adriatic Sea (latitude: $45^{\circ} 03^{\prime} \mathrm{N}$, longitude: $13^{\circ} 01^{\prime} \mathrm{E}$; depth: $27 \mathrm{~m}$ ), using a commercial fishing vessel belonging to the port of Chioggia. To reproduce the fishing procedures and to standardize the experimental setting, each tow lasted $40 \mathrm{~min}$ at a full speed of $11 \mathrm{~km} \mathrm{~h}^{-1}$. During the winter experiment, the seabed temperature was $9^{\circ} \mathrm{C}$ and the air temperature varied between 9 and $12^{\circ} \mathrm{C}$; during the summer experiment, the seabed temperature was $14^{\circ} \mathrm{C}$, and the air temperature varied between 26 and $28^{\circ} \mathrm{C}$. Intermolt adult specimens of Liocarcinus depurator were randomly collected from the discard and immediately employed for the survival experiment or for the physiological stress analyses. The designations of molt stage were according to those described by Mangum (1985). 
Survival tests

The mortality rates of $L$. depurator were assessed on 100 individuals per tow (3 replicates) immediately after the net was emptied on deck, and after 10 and 20 min of air exposure. In conformity with Bergmann $\&$ Moore (2001), individuals were deemed to be dead when no movement of scaphognatite and reaction to external stimulus were observed.

\section{Physiological stress assessment}

The physiological stress evaluation was carried out at two different stages of the fishing process: immediately after the end of the tow and during the sorting process. In the first group (hereafter referred to as "trawled"), individuals were immediately collected from the catch (within $3 \mathrm{~min}$ ) and put into tanks filled with sea water at the same temperature as the seabed water; hemolymph samples were withdrawn within 5 to $15 \mathrm{~min}$ of the end of each tow. The second group consisted of individuals (hereafter referred to as "trawled and emersed") which were left on deck exposed to air. Hemolymph samples were withdrawn continuously from randomly selected individuals: 5 to $45 \mathrm{~min}$ (winter experiment) and 5 to $25 \mathrm{~min}$ (summer), respectively, after the end of the tow. Hemolymph was withdrawn just once from each animal. During the same cruise, to test undisturbed individuals, not subjected to the catch stress induced by the trawl, baited creels were used and six specimens were collected and used as control group. During the summer experiment the same procedures were applied to the trawled group, but, due to the high mortality rate of the emersed crabs, the air exposure was shortened to $5 \mathrm{~min}$.

Hemolymph sampling and analysis

Hemolymph was collected from individuals using a $1 \mathrm{ml}$ syringe whose needle was inserted into the pericardium from the posterior side of the carapace to reduce the duration of handling and to collect postbranchial blood. The samples were immediately frozen and kept in liquid nitrogen until arrival in the lab where they were stored at $-20^{\circ} \mathrm{C}$ until used. Each hemolymph sample was generally used for the determination of all metabolites, but when the sample volume was too small, lactate and glucose measurements were preferred because they need less material to be assessed. The number of individuals sampled for each assay ranged between 23-41 as indicated in Fig. 2.

The concentration of total $\mathrm{NH}_{3} / \mathrm{NH}_{4}^{+}$nitrogen was determined colorimetrically using the method described by Solorzano (1969) with an absorbance reading at $634 \mathrm{~nm}$. Concentration values were determined by reference to a calibration plot obtained by suitable dilutions of a $1 \mathrm{mM} \mathrm{NH} \mathrm{NH}_{4} \mathrm{Cl}$ solution. The calibration plot was established in a concentration range so as to include the concentration in the experimental specimens.

L-lactate concentration was determined according to the method of Gutmann \& Wahlefeld (1974) based on the substrate oxidation to L-pyruvate catalyzed by lactate dehydrogenase in an assay medium made with $3.75 \mathrm{~g} / 100 \mathrm{ml}$ glycine, $2.0 \mathrm{ml} / 100 \mathrm{ml}$ hydrazine hydrate $(96 \%)$ buffered to $\mathrm{pH} 9.0$ with $\mathrm{NaOH}$ and containing $6 \mathrm{mM}$ EDTA to remove the interferences due to divalent cations in solution (Engel \& Jones, 1978). $\mathrm{NAD}^{+} 40 \mathrm{mM}$ and lactate dehydrogenase (510 U/mg diluted 1:2 in buffer) were also used.

The quantitative assay for D-glucose concentration is based on the hexokinase-catalyzed phosphorylation of the substrate (ATP is required as co-substrate) followed by the one-electron oxidation of glucose-6phosphate by the dehydrogenase that produces NADPH (Webster, 1996). The assay is carried out in $0.1 \mathrm{M}$ Tris/ $\mathrm{HCl} \mathrm{pH} 7.4$ containing $5 \mathrm{mM} \mathrm{MgSO}_{4}$. Both L-lactate and D-glucose assays were carried out with the internal standard method.

The concentration of the assayed compounds was calculated after extrapolating to zero the internal standard concentration and correction for dilutions. All spectrophotometric determinations were carried out with a Hewlett-Packard HP-8452 diode array spectrophotometer and all the reagents employed for the analyses were purchased from Sigma-Aldrich.

Statistical analysis

The mean value of the metabolic parameter was pairwise compared by Mann-Whitney U-test. The analyses were applied between the summer and winter trawled samples, and the summer and winter trawled and emersed samples. Due to the low number of specimens collected, the control group was not included in the analyses but presented in the figures 
simply as references. The limit of significance was considered at $P<0.001$.

\section{Results}

\section{Survival tests}

The short-term analyses of mortality rates highlighted the presence of a strong seasonal effect, since during the winter experiment, less than $2 \%$ of collected individuals died within $20 \mathrm{~min}$ of exposure to air, whereas during the summer experiments up to $96 \%$ died in the same time (Fig. 1).

\section{Physiological stress estimation}

The alteration of physiological state due to the stress condition occurring during the trawling or/and air exposure can be studied by measuring the concentration levels in the hemolymph of ammonia, Llactate, D-glucose. In Fig. 2 are shown the data obtained in "trawled" and "trawled and emersed" groups of animals. The creel-caught individuals are used as a control group for comparison with the other conditions, but only as a reference because of the reduced number of specimens. The "reference" data are the average of both the winter and summer values.

The animals collected by rapido trawling in winter showed average ammonia levels of $0.149 \pm 0.019$ mmol $1^{-1}$, slightly higher than the value registered in the control group $\left(0.107 \pm 0.007 \mathrm{mmol} \mathrm{l}^{-1}\right)$, but in summer the concentration in the hemolymph increased

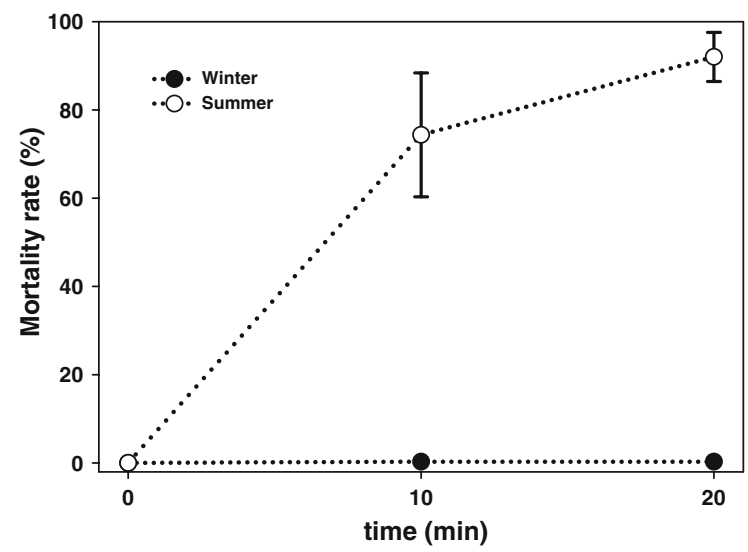

Fig. 1 Cumulative mortality rates $(\%)$ in Liocarcinus depurator caught by rapido trawl in summer $(\bigcirc)$ and winter $(\mathbf{O})$, at the end of the tow (0) and after 10 and $20 \mathrm{~min}$ of air exposure
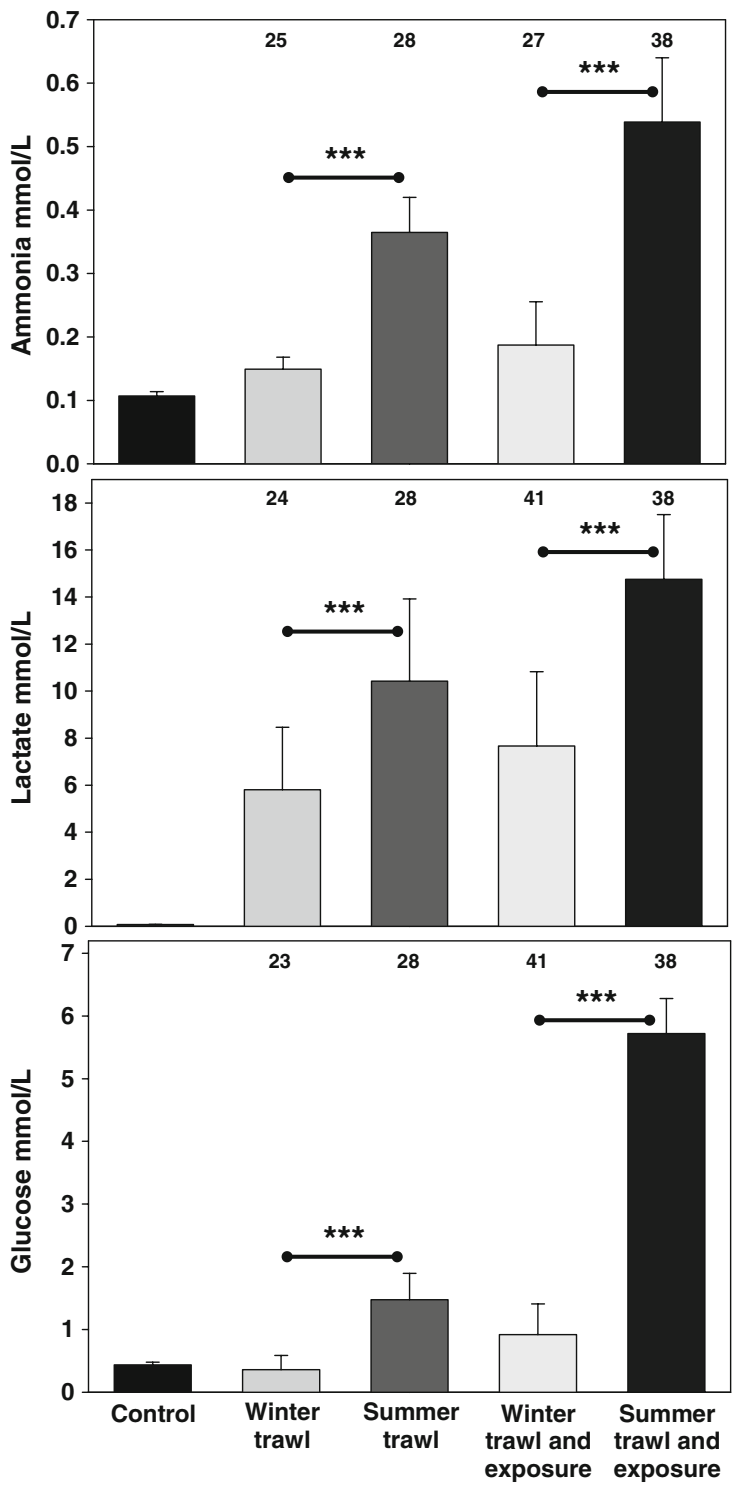

Fig. 2 Hemolymph ammonia, lactate, and glucose concentrations (mmol $1^{-1} \pm$ s.d.) measured on experimental crabs. The bars represent the value of concentrations for only trawled and trawled and emersed specimens both in summer and winter catches. The numbers over the bars represent the number of specimens considered while the control group was constantly constituted by six animals. The horizontal bars indicate the pairwise comparisons and the $* * *$ stand for the significance values $(P<0.001)$

up to $0.365 \pm 0.055 \mathrm{mmol} \mathrm{l}^{-1}$. In the group of individuals subjected to emersion after trawling, the ammonia value increased with respect to the nonexposed group, both in winter and summer, reaching values of $0.187 \pm 0.068 \mathrm{mmol} \quad 1^{-1}$ and $0.539 \pm 0.101 \mathrm{mmol}^{-1}$, respectively. 
Lactate was considerably low in the control group $\left(0.068 \pm 0.010 \mathrm{mmol} \mathrm{l}^{-1}\right)$ indicating a low stress condition in the animals captured by baited creels. As far as the winter experiment is concerned, the lactate concentration was $5.808 \pm 2.654 \mathrm{mmol}^{-1}$ in trawled individuals, but in air-exposed individuals the levels increased to $7.666 \pm 3.160 \mathrm{mmol} \mathrm{l}^{-1}$. A drastic lactate concentration increase was observed in summer: the trawled group showed a value of $10.422 \pm 3.497 \mathrm{mmol} \mathrm{l}^{-1}$, about twice the corresponding value in winter while the highest level was achieved in exposed individuals at $14.750 \pm$ $2.755 \mathrm{mmol} \mathrm{l}^{-1}$.

The concentration of glucose in hemolymph of control group was $0.435 \pm 0.044 \mathrm{mmol} \mathrm{l}^{-1}$. In winter the variation of glucose levels in trawled animals appears restrained $\left(0.359 \pm 0.227 \mathrm{mmol} \mathrm{l}^{-1}\right)$ and there was an increase up to $0.918 \pm 0.491 \mathrm{mmol} \mathrm{l}^{-1}$ in the air-exposed individuals. In summer the glucose levels exhibited remarkable differences as compared to winter experiments: the trawled group showed a value of $1.475 \pm 0.420 \mathrm{mmol}^{-1}$, about $300 \%$ higher than that in winter experiment, but the exposure to air produced a strong increase reaching the concentration of $5.719 \pm 0.559 \mathrm{mmol} \mathrm{l}^{-1}, 6-7$ times higher as compared to the corresponding winter group.

\section{Discussion}

The effects of air exposure on crustacean physiology have been accurately described in species that normally experience emersion in the intertidal and coastal fringes (e.g. Bridges \& Brand, 1981; DeFur, 1988; Taylor \& Spicer, 1988; Stillman \& Somero, 1996) as well as for subtidal species that could be forced to emersion as a consequence of commercial fishing activities (Schmitt \& Uglow, 1997; Morris \& Oliver, 1999a, b; Bergmann et al., 2001b; Danford et al., 2002). From this literature, it emerges that during sorting and shipping procedures benthic crustaceans, which inhabit stable environments and are virtually unable to cope with emersion, undergo a series of circulatory, respiratory, and metabolic impairments. These effects generally produce cumulative consequences on organisms and usually lead rapidly to mortalities.
Results obtained in the present study are consistent with previous findings about the physiological tolerance to emersion in Liocarcinus depurator (Bergmann et al., 2001b) and reveal the pronounced sensitivity of this species to mechanical stress during trawling action and to emersion during the sorting process. Moreover, they pointed out the extreme importance of the season in determining the disturbance magnitude on discarded species, underlining the role of the temperature effect in the fishing activities at temperate latitudes. In detail, survival tests showed the extent of seasonal influence, reflected in air and water temperature variations, on the survival chances of individuals involved in the fishing process. On the other hand, the physiological analyses provided the description of the metabolic disruption enhanced by higher temperatures during this stressful and unnatural event. During emersion the collapse of the gills produces a sudden breakdown of gas-exchange and excretion processes, with the consequent accumulation, at the level of tissues and hemolymph, of different metabolic end products (DeFur, 1988; Taylor \& Whiteley, 1989). The increase of lactate, $\mathrm{CO}_{2}, \mathrm{H}^{+}$concentrations normally occurs during the pronounced anaerobiosis together with the progressive accumulation of ammonia, urate, and amine in the hemolymph (Durand \& Regnault, 1998; Danford et al., 2002). Besides, fishing procedures like trawling and sorting constitute stressful events both for commercial and discarded species and generally increase animal activities and metabolism which finally produce addictive effects to the homeostasis disruption (Bergman et al., 2001b). The physiological response of sublittoral organisms to air exposure appears to be markedly species specific and the extent of sublethal levels of metabolites like ammonia and lactate shows a wide range. In portunid crabs, experimentally emersed for $18 \mathrm{~h}$, blood ammonia reaches values of $0.12 \mathrm{mmol}^{-1}$ in the intertidal Carcinus maenas and $1.3 \mathrm{mmol}^{-1}$ in the sublittoral Necora puber (Durand \& Regnault, 1998). Similarly, L. depurator subjected to ca. $40 \mathrm{~min}$ of emersion after fishing trawl presents value of $0.308 \mathrm{mmol} \mathrm{l}^{-1}$ of blood ammonia (Bergman et al., 2001b). All these values appear to be sublethal for the investigated species, in consideration with the small mortality rate recorded and with the complete recovery during reimmersion in water. Comparable values 
of blood ammonia have been measured in the present study both in trawled and trawled and emersed crabs during winter activities, suggesting a sublethal accumulation of nitrogen compounds during emersion. On the contrary, the severe increase of blood ammonia resulting from summer analyses could be a consequence of the accelerated metabolism at the higher temperatures and could partially be responsible for the pronounced mortality rate recorded.

The rapid switch to anaerobic metabolism during emersion produces a high rate of increase in blood lactate level in portunid crabs; however, these species show an efficient mechanism of repayment of the oxygen debt and a rapid restoration of normoxic conditions usually occurs during recovery in water. In particular, when sublittoral species such as $N$. puber are subjected to emersion, individuals show increasing value of blood lactate which reaches $9 \mathrm{mmol}^{-1}$ and $60 \mathrm{mmol}^{-1}$ after 4 and $18 \mathrm{~h}$ of air exposure, respectively (Durand \& Regnault, 1998). L. depurator appears to be more sensitive to emersion showing lactate concentrations in hemolymph of $6.2 \mathrm{mmol}^{-1}$ after $40 \mathrm{~min}$ in air following fishing trawling (Bergman et al., 2001b). Similar results are obtained in the present study for the winter samples. In addition, we have observed a prominent effect of the trawl motion rather than the emersion as the cause of stimulation of anaerobic metabolism (compare "trawl" and "trawl and exposure" data of Fig. 2). The mechanical solicitations and the elevated exercise inside the net seem to account for the principal fraction of the total oxygen debt. In summer these effects are significantly enhanced as a consequence of the thermal stress and accelerated metabolism.

In crustaceans, glycogen is the principal reserve of carbohydrates and constitutes the main source of energy during intense and protracted exercise; thus, high levels of circulating glucose represent a reliable indicator of energetic investment (Briffa \& Elwood, 2001, 2002). Although glucose concentration could depend on a number of physiological factors and should be carefully adopted as a stress indicator (Kallen et al., 1990; Chang, 1995), the quantification of hemolymph glucose has been used to assess the effect on trawling. Exercise and emersion on $L$. depurator, reveal a significant increase of this metabolite following highly disturbing treatments (Bergman et al., 2001b). Our results agree with the previous studies, but evidenced also for glucose mobilization remarkable differences as a function of the season. The hemolymph concentration in summer experiments, in fact, reached values 6-7 fold higher than that achieved in winter, underlining the effect of temperature on the metabolic disruption.

The evaporative water loss during the emersion constitutes an important cause of homeostasis disturbance and might partially contribute to increased metabolite concentration in crab hemolymph. However, on the basis of the limited reduction in body wet weight reported for L. depurator caught in the Clyde Sea and exposed to air for $1 \mathrm{~h}$ (Bergmann et al., 2001b), evaporative water loss is likely to be not the main factor in inducing the sharp metabolites' increase observed during the experiments here reported.

The integration of the survival tests with the physiological evaluation of the stress, occurring during trawling and sorting operations, suggests that a decline of $L$. depurator populations should be expected. This conclusion is further supported by the indication that $24 \mathrm{~h}$ are necessary for fully recovering the induced physiological impairment (Bergmann et al., 2001b) and that the occurrence of sublethal damages, such as limb loss, hamper the foraging efficiency and agonistic behavior of crabs (Pranovi et al., 2001; Bergmann et al., 2001a). However, data from surveys show a rather stable situation for the Northern Adriatic Sea (Raicevich, 2004). The hypothesis of a trade-off between energetic costs, associated with the fishing disturbance, and energetic benefits, due to discard supply can be put forward: the scavenging behavior of L. depurator (Bergmann et al., 2002) would, indeed, allow populations of this species to exploit the supplementary, low-energy expenditure, source of food given by individuals of other species discarded by fishing activities. A similar hypothesis has been proposed also for the scavenging starfish Asterias rubens in the North Sea (Ramsay et al., 2000).

The extension of this study to other species could make it possible to rank the non-target species on the basis of their vulnerability to fishing. Such rank could include physiological aspects based on field observation and mortality assessment, integrating former assessments mainly based on life-history and fragility features (Macdonald et al., 1996). In spite of the different mechanisms responsible for the resilience to 
fishing disturbance in populations of scavengers species, studies showing high discard mortality rates should be considered by the authorities to enforce the legislation aimed to reduce this adverse effect of fishing on non-target species. For instance, the summer fishing ban already implemented (1 month) in the Northern Adriatic Sea could be extended to the whole summer season, avoiding discard production in the period when specimens are more likely to suffer high mortality rates and physiological impairment.

\section{References}

Bergmann, M. \& P. G. Moore, 2001. Survival of decapod crustaceans discarded in the Nephrops fishery of the Clyde Sea area, Scotland. ICES Journal of Marine Science 58: 163-171.

Bergmann, M., D. J. Beare \& P. G. Moore, 2001a. Damage sustained by epibenthic invertebrates discarded in the Nephrops fishery of the Clyde Sea, Scotland. Journal of Sea Research 45: 105-118.

Bergmann, M., A. C. Taylor \& P. G. Moore, 2001b. Physiological stress in decapod crustaceans (Munida rugosa and Liocarcinus depurator) discarded in the Clyde Nephrops fishery. Journal of Experimental Marine Biology and Ecology 259: 215-229.

Bergmann, M., S. K. Wieczorek, P. G. Moore \& R. J. A. Atkinson, 2002. Utilisation of invertebrates discarded from the Nephrops fishery by variously selective benthic scavengers in the west of Scotland. Marine Ecology Progress Series 233: 185-198.

Bridges, C. R. \& A. R. Brand, 1981. The effect of hypoxia on haemolymph oxygen consumption and haemolymph lactate levels of some marine Crustacea. Comparative Biochemistry and Physiology A 65: 157-168.

Briffa, M. \& R. W. Elwood, 2001. Decision rules, energy metabolism and vigor of hermit crab fights. Proceedings of the Royal Society of London, Series B 268: 1841-1848.

Briffa, M. \& R. W. Elwood, 2002. Power of shell-rapping signals influences physiological costs and subsequent decisions during hermit crab fights. Proceedings of the Royal Society of London, Series B 269: 2331-2336.

Burnett, L. E., 1988. Physiological responses to air exposure: acid-base status and the role of branchial water stores. American Zoologist 28: 125-135.

Cabral, H. N., C. M. Teixeria, R. Gamito \& M. J. Costa, 2002. Importance of discards of a beam trawl fishery of organic matter into nursery areas within the Tagus estuary. Hydrobiologia 475/476: 449-455.

Chang, E. S., 1995. Physiological and biochemical changes during the molt cycle in decapod crustaceans: an overview. Journal of Experimental Marine Biology and Ecology 193: 1-14.

Danford, A. R., L. Hagerman \& R. F. Uglow, 2002. Effects of emersion and elevated haemolymph ammonia on haemocyanin-oxygen affinity of Cancer pagurus. Marine Biology 141: 1019-1027.
DeFur, P. L., 1988. Systemic respiratory adaptations to air exposure in intertidal decapod crustaceans. American Zoologist 28: 115-124.

Durand, F. \& M. Regnault, 1998. Nitrogen metabolism of two portunid crabs, Carcinus maenas and Necora puber, during prolonged air exposure and subsequent recovery: a comparative study. Journal of Experimental Biology 201: 2515-2528.

Engel, P. C. \& J. B. Jones, 1978. Causes and elimination of erratic blanks in enzymatic metabolite assays involving the use of NAD+ in alkaline hydrazine buffers: improved conditions for the assay of L-glutamate, L-lactate and other metabolites. Analytical Biochemistry 88: 475-484.

Gamito, R. \& H. Cabral, 2003. Mortality of brown-shrimp discards from the beam trawl fishery in the Tagus estuary, Portugal. Fisheries Research 63: 423-427.

Gutmann, I. \& A. W. Wahlefeld, 1974. L-(+)-lactate: determination with lactate dehydrogenase and NAD+. In Bergmeier, H. U. (ed.), Methods of Enzymatic Analysis. Academic Press, New York: 1464-1468.

Hagerman, L., T. Søndergaard., K. Weile, D. Hosie \& R. F. Uglow, 1990. Aspects of blood physiology and ammonia excretion in Nephrops norvegicus under hypoxia. Comparative Biochemistry and Physiology 97: 51-55.

Hall-Spencer, J. M., C. Froglia, R. J. A. Atkinson \& P. G. Moore, 1999. The impact of Rapido trawling for scallops, Pecten jacobaeus (L.), on the benthos of the Gulf of Venice. ICES Journal of Marine Science 56: 111-124.

Kaiser, M. J. \& B. E. Spencer, 1995. Survival of by-catch from a beam trawl. Marine Ecology Progress Series 126: $31-38$.

Kallen, J. L., S. L. Abrahamse \& F. Van Herp, 1990. Circadian rhythmicity of the crustacean hyperglycemic hormone $\mathrm{CHH}$ in the hemolymph of the crayfish. Biological Bulletin 179: 351-357.

Jennings, S. \& M. J. Kaiser, 1998. The effects of fishing on marine ecosystems. Advances in Marine Biology 34: 201351.

Jennings, S., T. A. Dinmore, D. E. Duplisea, K. J. Warr \& J. E. Lancaster, 2001. Trawling disturbance can modify benthic production processes. Journal of Animal Ecology 70: 459-475.

MacDonald, D. S., M. Little, M. C. Eno \& K. Hiscock, 1996. Disturbance of benthic species by fishing activities: a sensitivity index. Aquatic Conservation 6(4): 257-268.

Mangum, C. P., 1985. Molting in the blue crab Callinectes sapidus: a collaborative study of intermediary metabolism, respiration and cardiovascular function, and ion transport. Preface Journal of Crustacean Biology 5: 185-187.

McMahon, B. R., 2001. Respiratory and circulatory compensation to hypoxia in crustaceans. Respiration Physiology 128: 349-364.

Morris, S. \& S. Oliver, 1999a. Circulatory, respiratory and metabolic response to emersion and low temperature of Jasus edwardsii: simulation studies of commercial shipping methods Comparative Biochemistry and Physiology A-Molecular and Integrative Physiology 122: 299-308.

Morris, S. \& S. Oliver, 1999b. Respiratory gas transport, haemocyanin function and acid-base balance in Jasus edwardsii during emersion and chilling: simulation 
studies of commercial shipping methods. Comparative Biochemistry and Physiology A-Molecular and Integrative Physiology 122: 309-321.

Pauly, D. \& V. Christensen, 1995. Primary production required to sustain global fisheries. Nature 374: 255-257.

Pikitch, E. K., C. Santora, E. A. Babcock, A. Bakun, R. Bonfil, D. O. Conover, P. Dayton, P. Doukakis, D. Fluharty, B. Heneman, E. D. Houde, J. Link, P. A. Livingston, M. Mangel, M. K. McAllister, J. Pope \& K. J. Sainsbury, 2005. Ecosystem-based fishery management. Science 305: 346-347.

Pranovi, F., S. Raicevich, G. Franceschini, P. Torricelli \& O. Giovanardi, 2001. Discard composition and damage to non-target species in the "rapido" trawl fishery. Marine Biology 139: 863-875.

Queirós, A. M., J. G. Hiddink, H. Hinz \& M. J. Kaiser, 2006. The effects of chronic bottom trawling disturbance on biomass, production and size spectra of invertebrate infauna communities from different habitats. Journal of Experimental Marine Biology and Ecology 335: 91-103.

Raicevich, S., 2004. Assessment of ecological disturbance in marine environments. Ph.D. thesis, University " $\mathrm{Ca}$ ' Foscari”, Venice.

Ramsay, K., M. J. Kaiser, A. D. Rijnsdorp, J. A. Craeymeersch \& J. Ellis, 2000. Impact of trawling on populations of the invertebrate scavenger Asterias rubens. In Kaiser, M. J. \& S. J. de Groot (eds), The effects of fishing on non-target species and habitats: biological, conservation and socioeconomic issues. Fishing News Books: 151-162.

Schmitt, A. S. C. \& R. F. Uglow, 1997. Haemolymph constituent levels and ammonia efflux rates of Nephrops norvegicus during emersion. Marine Biology 127: 403-410.

Solorzano, L., 1969. Determination of ammonia in natural waters by the phenolhypochlorite method. Limnology and Oceanography 4: 799-801.
Stillman, J. H. \& G. N. Somero, 1996. Adaptation to temperature stress and aerial exposure in congeneric species of intertidal porcelain crabs (genus Petrolisthes): correlation of physiology, biochemistry and morphology with vertical distribution. Journal of Experimental Biology 199: 1845-1855.

Taylor, A. C. \& J. I. Spicer, 1987. Metabolic responses of the prawns Palaemon elegans and P. serratus (Crustacea: Decapoda) to acute hypoxia and anoxia. Marine Biology 95: 521-530.

Taylor, A. C. \& J. I. Spicer, 1988. Functional significance of a partial-emersion response in the prawn Palaemon elegans (Crustacea: Palaemonidae) during environmental hypoxia. Marine Ecology Progress Series 44: 141-147.

Taylor, E. W. \& M. G. Whiteley, 1989. Oxygen transport and acid-base balance in the haemolymph of the lobster, Homarus gammarus, during aerial exposure and resubmersion, Journal of Experimental Biology 144: 417-436.

Tillin, H. M., J. G. Hiddink, M. J. Kaiser \& S. Jennings, 2006. Chronic bottom trawling alters the functional composition of benthic invertebrate communities on a sea basin scale. Marine Ecology Progress Series 318: 31-45.

Webster, S. G., 1996. Measurement of crustacean hyperglycaemic hormone levels in the edible crab Cancer pagurus during emersion stress. Journal of Experimental Biology 199: 1585-1597.

White, P. S. \& S. T. A. Pickett, 1985. Natural disturbance and patch dynamics: an introduction. In White P. S. \& S. T. A. Pickett (eds), The Ecology of Natural Disturbance and Patch Dynamics. Academic Press, New York: 1-3.

Williams, N., 1998. Overfishing disrupts entire ecosystems. Science 279: 809 . 